\title{
Forecasting cetacean abundance patterns to enhance management decisions
}

\author{
E. A. Becker ${ }^{1, *}$, D. G. Foley ${ }^{2,3}$, K. A. Forney ${ }^{1}$, J. Barlow ${ }^{4}$, J. V. Redfern ${ }^{4}$, \\ C. L. Gentemann ${ }^{5}$ \\ ${ }^{1}$ NOAA National Marine Fisheries Service, Southwest Fisheries Science Center, 110 Shaffer Road, Santa Cruz, \\ California 95060, USA \\ ${ }^{2}$ Joint Institute for Marine and Atmospheric Research, University of Hawaii, 1000 Pope Road, Honolulu, Hawaii 96822, USA \\ ${ }^{3}$ NOAA National Marine Fisheries Service, Southwest Fisheries Science Center, 1352 Lighthouse Avenue, Pacific Grove, \\ California, 93950, USA \\ ${ }^{4}$ NOAA National Marine Fisheries Service, Southwest Fisheries Science Center, 3333 N. Torrey Pines Court, La Jolla, \\ California 92037, USA \\ ${ }^{5}$ Remote Sensing Systems Inc., 444 Tenth Street, Suite 200, Santa Rosa, California 95401, USA
}

\begin{abstract}
Species-environment models are increasingly recognized as valuable tools for assessing protected species distributions and developing measures to reduce or avoid adverse impacts. Cetacean-habitat models can provide a finer spatial resolution than traditional abundance estimates, but model predictions are generally based on past observations rather than current or projected ocean conditions. We present and evaluate methods for near real-time and forecast models of cetacean distribution based on remotely sensed and modeled oceanographic data. Recent advancements in processing satellite-derived data (e.g. microwave/infrared blended sea surface temperature [SST] products) have virtually eliminated data gaps due to cloud cover, allowing short-term forecasts based on single-day snapshots of oceanic conditions. Ocean circulation models (e.g. the Regional Ocean Modeling System [ROMS]) allow medium-range forecast predictions of oceanic variables, including SST, chlorophyll and salinity. We developed habitat models for striped dolphin, fin whale and Dall's porpoise using line-transect data collected from July to November 1991-2005 in the California Current Ecosystem. We incorporated daily blended SST data and monthly ROMS SST forecasts as input variables to predict relative species density in 2008. Forecast ability was assessed by the models' ranked predictions across 8 geographic strata, and by visual inspection of predicted and observed distributions. For all 3 species, there was a significant correlation between model predictions using daily blended SSTs and actual survey observations $(p<0.05)$. Longer-term $(3-4 \mathrm{mo})$ predictions also showed good concordance with observed sighting locations. Cetacean-habitat models that allow weekly to monthly forecasting of cetacean abundance can greatly enhance short-term decision-making and advanced mitigation planning.
\end{abstract}

KEY WORDS: Cetacean abundance - Habitat-based density model - Generalized additive model · GAM $\cdot$ California Current $\cdot$ Remote sensing $\cdot$ Fin whale $\cdot$ Striped dolphin $\cdot$ Dall's porpoise

\section{INTRODUCTION}

Many protected marine species, including marine mammals, sea turtles, fish and seabirds, exhibit marked variation in their oceanic distributions on seasonal, interannual and decadal time scales
(Forney 1999, Pyper \& Peterman 1999, Forney 2000, Maravelias et al. 2000, Rosenkranz et al. 2001, Koslow et al. 2002). Such temporal and spatial variability is a major source of uncertainty in ecological research and marine resource management (Peterman \& Bradford 1987, Forney et al. 1991, Edwards \& 
Perkins 1992, Taylor \& Gerrodette 1993, Forney 1999, Ralls \& Taylor 2000). Quantitative species-habitat models are increasingly recognized as valuable tools for assessing protected species distributions and assisting decision-makers in the development and implementation of measures to reduce adverse impacts (e.g. fishery bycatch, ship strikes, seismic activities and navy exercises) (Torres et al. 2003, Kaschner et al. 2006, Barlow et al. 2009). Although our knowledge of the ecological processes and trophic linkages influencing cetacean distributions is limited to a few species (e.g. Gaskin 1987, Murison \& Gaskin 1989, Baumgartner \& Mate 2003, Baumgartner et al. 2003, Croll et al. 2005), habitat models can be used to help establish marine protected areas (Hooker et al. 1999, Cañadas et al. 2002), facilitate the assessment of potential impacts from navy operations (Department of the Navy 2010) and evaluate the risk of ship strikes (Redfern et al. unpubl. data). Quantitative models of species-habitat relationships are commonly based on cetacean sighting and oceanographic data collected during line-transect surveys, and they provide a finer spatial resolution of cetacean density estimates than standard line-transect methods (Hedley et al. 1999, Forney 2000, Ferguson et al. 2006, Barlow et al. 2009). However, the modeled densities are generally static, based on past observations, rather than dynamic, based on current or projected ocean conditions. Habitat-based density models that could provide near real-time (hereafter 'nowcast') and forecast predictions would significantly improve the ability of scientists and resource managers to analyze and make decisions related to cetacean distributions.

Given the time and expense of collecting and processing in situ oceanographic data, nowcast and forecast predictions may only be possible through the use of environmental data derived from satellites and dynamic physical oceanographic models. Satellite data provide broad spatial coverage in near realtime, whereas in situ data are limited to the times and areas surveyed. Becker et al. (2010) recently demonstrated that remotely sensed sea surface temperature (SST) data are as effective at capturing speciesenvironment relationships as in situ SST data. However, data gaps due to cloud cover have been considered one of the main disadvantages associated with using satellite data from passive infrared sensors (Becker et al. 2010), particularly in regions off the US West Coast, where persistent low cloud cover is often associated with coastal upwelling areas. Recent advances in processing satellite-derived data using microwave and infrared sensors have virtually eliminated data gaps due to cloud cover (Gentemann et al.
2009), allowing short-term SST forecasts at $9 \mathrm{~km}$ spatial resolution based on single-day snapshots of oceanic conditions.

Ocean circulation models such as the Regional Ocean Modeling System (ROMS; Chao et al. 2009) allow 1-9 mo forecast predictions of oceanic variables at $12.5 \mathrm{~km}$ spatial resolution, including SST, salinity, chlorophyll, oxygen, mixed layer depth, phytoplankton and zooplankton. The inclusion of such predictor variables in habitat models is expected to improve their nowcast and forecast ability; however, proof-of-concept is required. As a test case for medium-term (3-4 mo) forecasts, we implemented habitat models in simulated forecast mode using SST output from ROMS. If SST forecasts are shown to be effective for species with strong SST associations (e.g. Dall's porpoise Phocoenoides dalli; Forney 2000, Barlow et al. 2009, Becker et al. 2010), other model-derived physical and biological variables may improve forecasts for species whose habitat associations are more complex.

In this study we develop and present methods to improve upon the currently available static habitat models by providing nowcast and forecast capabilities that are based on remotely sensed and modeled oceanographic data. As test cases, we selected 3 California Current Ecosystem (CCE) species for which SST has been a key predictor variable (defined as having the greatest effect on the mean response) in previous habitat models: striped dolphin Stenella coeruleoalba, Dall's porpoise, and fin whale Balaenoptera physalus (Forney 2000, Barlow et al. 2009, Becker et al. 2010). Based on the functional forms of modeled relationships between encounter rates and SST, striped dolphins have an affinity for warm offshore waters, Dall's porpoises are primarily found in cooler, upwelling-modified water, and fin whale encounter rates are greatest in moderate-temperature waters within the CCE (Forney 2000, Becker et al. 2010). We evaluated the models' forecast capabilities at 3 temporal scales: (1) nowcast (same day), (2) short-term (2-4 wk) and (3) medium-term (3-4 mo). Results from this preliminary study provide a basis for other habitat modeling efforts and may lead to advances in nowcast and forecast predictions.

\section{MATERIALS AND METHODS}

\section{Field methods}

Cetacean sighting data used to construct the habitat models were collected within the CCE study area 
(1 $141800 \mathrm{~km}^{2}$; Fig. 1) from late July through early December 1991，1993，1996， 2001 and 2005 (see Barlow \& Forney 2007) using systematic ship-based line-transect methods (Buckland et al. 2001). Experienced observers collected cetacean sighting data using line-transect procedures that were consistent in all surveys (Kinzey et al. 2000, Barlow \& Forney 2007). In summary, 1 starboard and 1 port observer searched for animals using pedestal-mounted $25 \times$ 150 binoculars while a third observer/data recorder searched from a central position using unaided eye and $7 \times 50$ handheld binoculars. A team of 6 ob-

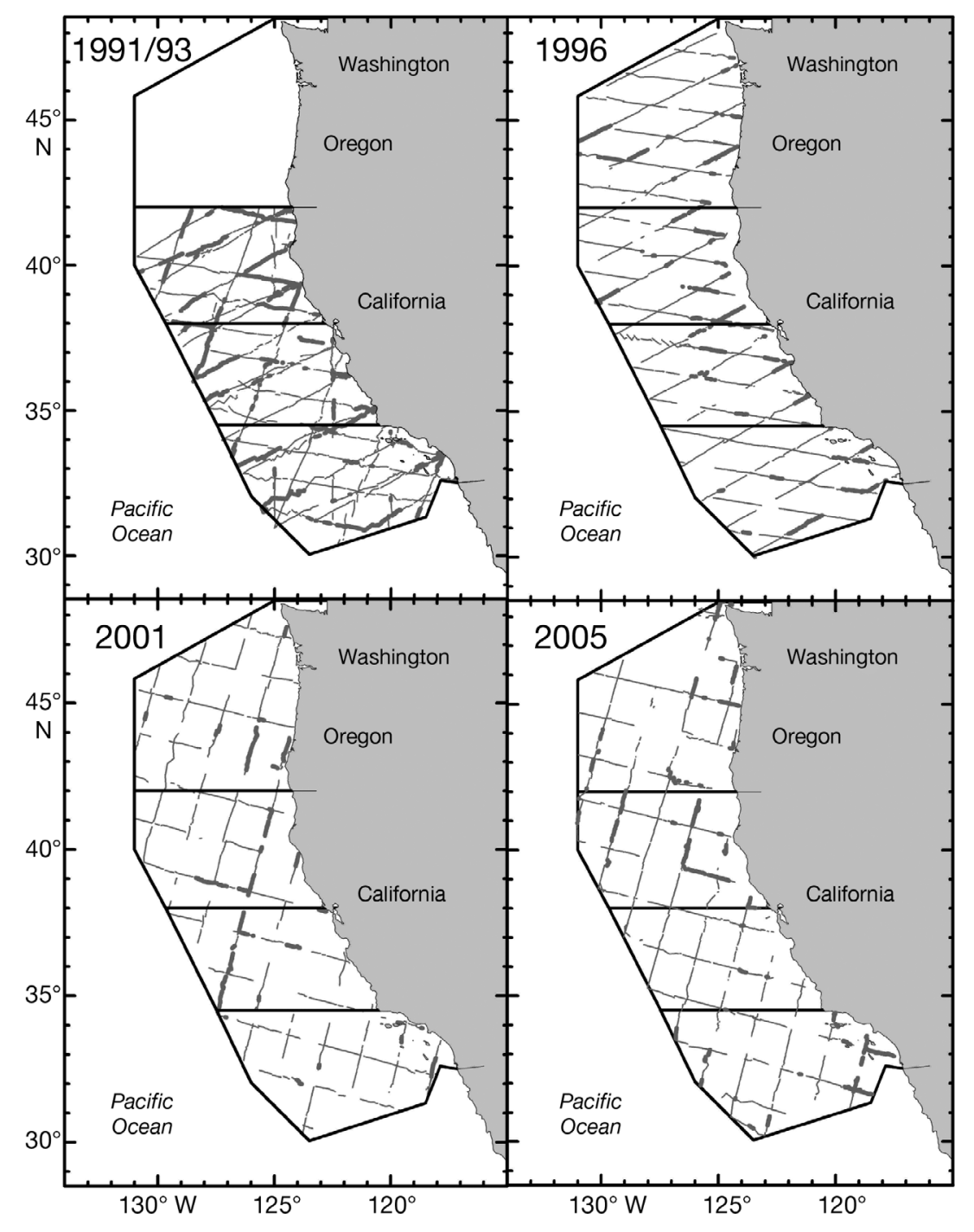

Fig. 1. Completed transects for the Southwest Fisheries Science Center shipboard surveys conducted late July through early December 1991 and 1993, 1996, 2001 and 2005 off the US West Coast. Thick gray transect lines were surveyed in Beaufort sea states of 0 to 2 and thin gray lines were surveyed in Beaufort 3 to 5 . Black lines on all maps indicate the boundaries of 4 geographic strata used for line-transect abundance estimation (Barlow \& Forney 2007) servers rotated every 40 min among the 3 positions, so that each observer received a $2 \mathrm{~h}$ rest period during the rotations. All 'on-effort' observations (i.e. those made by assigned observers using systematic line-transect methods during acceptable survey conditions) were made from the flying bridge of the ship. When cetaceans were detected within $5.5 \mathrm{~km}$ of the trackline, the ship typically diverted from the transect line in 'closing mode' to estimate group size and identify the species present to the lowest taxonomic level possible. If the observers were not able to confirm species, a higher taxonomic level, e.g. Mesoplodon spp., was recorded. Group size was estimated independently by the observers and was defined to include all animals at the sighting location that were behaviorally associated with one another (traveling, foraging, milling, resting, etc.). Models were developed using only sightings made while 'on effort' and identified to species.

\section{Analytical methods}

We use the term 'habitat-based density models' to distinguish between other commonly used terminology such as 'habitat models' that are often based only on presence/ absence, and 'spatial density models' that typically include longitude and latitude as fixed predictor variables. The ultimate goal of a habitat-based density model is to predict species density based on dynamic environmental variables. Currently, the static, multi-year average models that are based on 5 survey years in the CCE with varying oceanic conditions (Barlow et al. 2009, Forney et al. 2012, this Theme Section) represent the best predictions of cetacean distributions in any future year. In the present study, we compare the predictions from these 'average models' to new model predictions that are based on dynamic measures of oceanic conditions in a future year (2008), specifically the daily blended SST data (nowcast and short-term forecast models, evaluated for daily 
and weekly periods, respectively) and monthly ROMS SST predictions (medium-term forecast models, evaluated over a few months). All models of relative density were evaluated based on novel survey data collected within the same study area from 29 July through 30 November 2008, using line-transect methods identical to those used in the previous 1991-2005 surveys (Fig. 2). The analytical methods used to build the habitat-based density models are similar to those used previously for the CCE (Barlow et al. 2009, Becker et al. 2010) and are briefly summarized below.

Data sources for initial model development

To create samples for modeling, data from the 5 shipboard surveys were divided into continuous effort segments of approximately $5 \mathrm{~km}$ as described in Becker et al. (2010). The resulting data set contained a total of 11252 segments ranging in length from 0.06 to $7.5 \mathrm{~km}$, with the majority ( $75 \%$ ) equal to the target length of $5 \mathrm{~km}$. For each segment, we calculated the total number of groups of each species and the average group size, calculated as the mean group size estimate for all observers who made an estimate.

Models included 2 static habitat variables (water depth and bathymetric slope) and 1 dynamic variable (remotely sensed SST; acquired from National Oceanic and Atmospheric Administration/National Environmental Satellite, Data and Information Service/Pathfinder v5). Water depth in each segment was obtained from the ETOPO2 2-minute global relief data (US Department of Commerce NOAA, NGDC 2006). Bottom slope was calculated as the magnitude of the bathymetry gradient (meters rise per meter horizontal) using the gradient operator tool in GMT (Generic Mapping Tools; Wessel \& Smith 1998). Individual depth and bottom slope values estimated at the midpoint of each segment were retrieved using the 'sample' tool in ArcGIS (Version 9.3, ESRI).

We used 8 d running average SST composites centered on the date of each survey segment obtained at a spatial resolution of $0.25^{\circ}$ surrounding the segment midpoint. We selected $8 \mathrm{~d}$ composites since they provide consistent representation of average survey-day conditions without sacrificing sample size (Becker et al. 2010). Given the finer spatial resolution of the SST data used for nowcast and forecast predictions (9 and $12.5 \mathrm{~km}$, respectively), we also constructed the models using $0.10^{\circ} \mathrm{SST}$ composites to evaluate potential bias. Consistent with the findings of Becker et al.

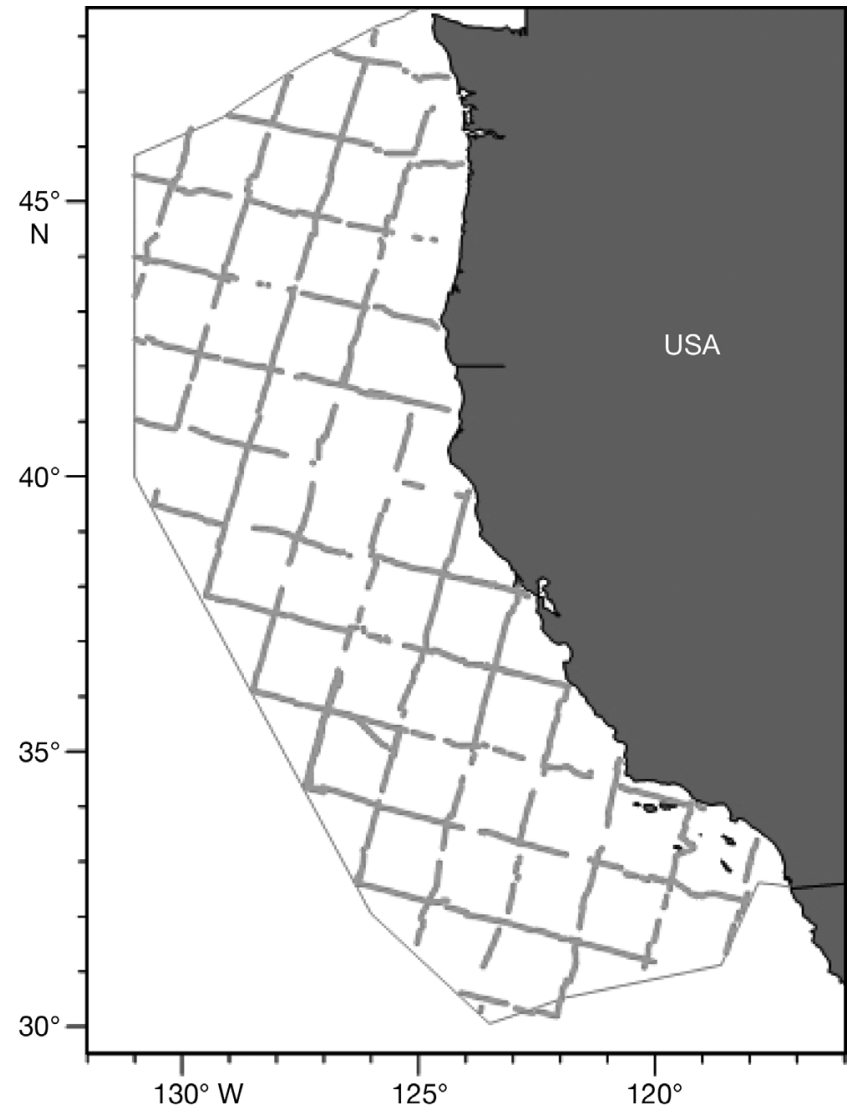

Fig. 2. Completed transects (gray lines) for the Southwest Fisheries Science Center shipboard survey conducted from 29 July through 30 November 2008 off the US West Coast

(2010), the models for all 3 species showed similar functional relationships between SST and the response variables, and predictor variables in the final 0.10 and $0.25^{\circ}$ models were identical. The models built with $0.25^{\circ} \mathrm{SST}$ were ultimately carried forward for this analysis because they provided larger sample sizes for model development. Average Beaufort sea state for each segment was also included as a continuous predictor variable in our models to account for the variability in sighting conditions (Barlow et al. 2001), but segments with average sea state values exceeding Beaufort 5 were excluded from the analysis (Barlow \& Forney 2007). Because of detection difficulties in rough seas, the abundance of Dall's porpoise is usually estimated using only search effort conducted in calm seas (Beaufort 0-2; Barlow \& Forney 2007); however, models built using only segments with these Beaufort conditions would not have captured the full range of habitat types for Dall's porpoise in the study area. We therefore constructed the Dall's porpoise models using the full range of sea state conditions (Beaufort 0-5) for this model comparison. 


\section{Model development}

Separate encounter rate and group size generalized additive models (GAMs; Hastie \& Tibshirani 1990) were built using the step.gam function in the statistical software package S-PLUS (Professional Edition Version 6.1, Release 1 for Windows, Insightful) following the methods of Ferguson et al. (2006) and Becker et al. (2010). Akaike's Information Criterion (AIC; Akaike 1973) was initially used in step.gam as the basis for selecting among potential combinations of predictor variables and varying degrees of freedom. AIC is typically used to obtain the best model fit with the fewest parameters; to ensure that all potentially important variables were represented, we included all variables within 2 AIC units of the original 'best' model in the final predictive models (when the same variable was included with various degrees of smoothing, the highest smooth was selected).

Encounter rate models were built using all transect segments, regardless of whether they included sightings, whereas group size models were built using only those segments that included sightings. The encounter rate data were fit using Poisson GAMs in which overdispersion was corrected using a quasilikelihood model. The natural log of the segment length was included as an offset term to account for the varying length $(0.06$ to $7.5 \mathrm{~km})$ of the segments. Group size models were built using the natural log of group size as the response variable and an identity link function (Ferguson et al. 2006).

Density (number of animals per $\mathrm{km}^{2}$ ) is typically estimated with standard line-transect formulae that include correction factors for the probability of detection $(f(0)$ and $g(0)$; Buckland et al. 2001). These correction factors are constants and would not differ among the models compared in this study, so for simplicity our comparisons were based on a measure of relative density, equal to the total number of animals encountered per $\mathrm{km}$ surveyed and calculated as the product of the model-derived encounter rate and group size. Segment-specific relative density estimates for each species were interpolated to the entire study area using Surfer 9.0 (Version 9, Golden Software). Contour grids were created at a resolution of $25 \mathrm{~km}$ using inverse distance weighting to the second power, and all data within a search radius of $2^{\circ}$ latitude $(222 \mathrm{~km})$ were used for interpolation to include data from more than one transect line (transect spacing during the 5 survey years was generally less than $222 \mathrm{~km}$; Barlow et al. 2009). This interpolation method provided a synoptic view of 'summer/fall' species densities for each survey year, spanning approximately 4 mo between late July and early December (Barlow et al. 2009, Forney at al. 2012).

Average models

For the static, 1991-2005 average models, relative density prediction grids were created for each of the individual survey years (1991, 1993, 1996, 2001 and 2005), and the individual grid cells were averaged across all years to calculate an average relative density for each species. To eliminate occasional overspecification ('bull's eye' effects), a $5 \times 5$ pixel (25 km pixel resolution) moving average filter with equal weights was applied to the final average prediction grid. This interpolation process provided smoothed multi-year average relative density predictions for the 3 species, taking into account both the varying oceanographic conditions and the different levels of sampling coverage achieved during the 5 Southwest Fisheries Science Center cetacean surveys. Interannual and inter-decadal variations in oceanic conditions and biological productivity have been documented in the study area (Roemmich \& McGowan 1995, Chavez et al. 2003), and variability in oceanic conditions and cetacean distributions was observed amongst the 5 survey years (Barlow et al. 2009). The average relative density models (hereafter 'average models') thus incorporated interannual variability and are somewhat analogous to an oceanographic climatology, but measuring cetacean densities rather than oceanographic properties. On average, they currently represent the best spatially explicit predictions of relative cetacean density for each of the 3 species.

\section{Nowcast models}

Nowcast models were created to evaluate daily forecast capabilities of models that used dynamic, satellite-derived SST data as a predictor. The SST data are based on optimal interpolation methods (Reynolds \& Smith 1994) that blend high-resolution infrared data with microwave data to provide a daily, gap-free SST product at $9 \mathrm{~km}$ spatial resolution (Gentemann et al. 2009). Data from the 2 types of sensors are used to maximize the strengths in their respective measurements. The $9 \mathrm{~km}$ infrared satellite data allow for accurate measurement of mesoscale features, but are unable to measure through clouds. The $25 \mathrm{~km} \mathrm{mi-}$ crowave data are valuable because SST can be mea- 
sured in both clear and cloudy conditions. These daily 'blended $\mathrm{SST}^{\prime}$ values were highly correlated (R > $90 \%$ ) with 8 d composite SST values for the 2008 survey, indicating that the former provided a good representation of SST conditions as measured by the type of data used to construct the models. Nowcast predictions of relative density for the 2008 survey were created by matching the daily blended $9 \mathrm{~km}$ SST data to each day and time of the transect segments for the 2008 survey. The predicted values for each transect segment were then interpolated to the entire study area using the same methods as described above for the 1991-2005 average models. The density contours thus represent composite densities based on daily predictions for the entire 2008 survey.

\section{Short-term forecast models}

Short-term (weekly) forecast models were also developed with the satellite-derived blended SST data, but relative density predictions were based on SST values for a single day (1 September 2008) and model performance was considered relative to the entire subsequent month (a short-term forecast range of up to $4 \mathrm{wk}$ ). Interpolation was performed based on transect segment predictions as described above for the nowcast models.

\section{Medium-term forecast models}

Medium-term (3-4 mo) forecast capabilities were based on SST predictions (12.5 km resolution) generated in July 2008 by the ROMS (e.g. Chao et al. 2009) for the surveyed months of October and November 2008. Relative density predictions for each of the 2 months were then interpolated as described for the previous models. To simulate a true forecast prediction for which location-specific sea state data would not be available, predictions were based on the weighted average sea state for the 1991-2005 surveys, which were the basis for the original model development.

Model evaluation

We evaluated the performance of the 3 dynamic models (nowcast, short-term forecast and mediumterm forecast) relative to the static average model using a combination of the following methods: (1) visual inspection of the observed 2008 sighting loca- tions relative to the model-predicted patterns of relative density for the corresponding time period, (2) the ratio of each of the model-based relative density predictions to the line-transect relative density estimate for the entire 2008 study area, and (3) a nonparametric Spearman rank correlation test to evaluate the models' ability to capture spatial patterns.

Visual inspections were made by overlaying the predicted relative density contours and the subset of 2008 sightings within the corresponding prediction period. The human eye is often superior to statistics for comparing patterns (Wang et al. 2004), particularly in data-limited cases in which more advanced spatial methods cannot be used. For the nowcast model, the overlay included all observed sightings for the 3 species during the 2008 surveys. Short-term forecast capabilities were evaluated by comparing the single-day prediction contours with the 2008 sightings made during the subsequent month (September). Medium-range forecasts were evaluated separately for a 3 mo forecast period (October sightings) and 4 mo forecast period (November sightings).

The average relative density of each species within the entire study area was compared with relative density estimates derived directly from the 2008 survey data (using the product of observed encounter rate and group size) for the dynamic nowcast/ forecast models and the static average model. Although these comparisons do not provide information on the models' ability to capture spatial patterns, in concert with the sighting plots, they provide a quantitative measure for evaluating overall, study area-wide model accuracy. A ratio of 1 for the linetransect estimate over the model prediction indicates perfect agreement between methods, whereas a ratio of less than 1 indicates that model densities are overpredicted relative to the observed patterns, and a ratio greater than 1 indicates that the model densities are under-predicted.

Correlation tests were only possible for the nowcast model because of sample-size limitations for the single-month prediction periods of the short-term and medium-range forecast models. The Spearman rank correlation test was based on a comparison of ranked predictions of estimated relative abundance (the product of the observed number of sightings and group size), calculated from the 2008 survey data and derived by the nowcast model, within 8 geographic strata of the $1141800 \mathrm{~km}^{2}$ study area (Fig. 3): 4 north-south strata consistent with those used for line-transect abundance estimation (Barlow \& Forney 2007), and an offshore-onshore division at the $2000 \mathrm{~m}$ isobath, as a proxy for the shelf-break. The 4 
north-south strata include waters off Oregon and Washington $\left(322200 \mathrm{~km}^{2}\right.$ north of $\left.42^{\circ} \mathrm{N}\right)$, northern California $\left(258100 \mathrm{~km}^{2}\right.$ south of $42^{\circ} \mathrm{N}$ and north of Point Reyes at $\left.38^{\circ} \mathrm{N}\right)$, central California $\left(243000 \mathrm{~km}^{2}\right.$ between Point Conception at $34.5^{\circ} \mathrm{N}$ and Point Reyes) and southern California (318500 km² south of Point Conception).

In summary, for the nowcast and forecast analyses, all relative density predictions were processed using the same smoothing techniques and were visually compared with plots of actual and 1991-2005 modeled averages. In addition to the visual evaluations, we compared model-predicted relative density estimates with those derived directly from the survey data without environmental predictors, and evaluated performance based on the ratios of observed to predicted relative density. For the study area predictions, nowcast ability was also assessed by the models' ranked predictions across 8 geographic strata.

\section{RESULTS}

Information on search effort, number of species sighted and associated line-transect abundance estimates for the 1991-2005 shipboard surveys has been previously summarized by Barlow \& Forney (2007). The 3 species we used for model development were selected based on their association with SST as shown from previous habitat modeling efforts (Forney 2000, Becker 2007, Barlow et al. 2009, Becker et al. 2010). The variables included in our final models, as well as their functional forms, were similar to those resulting from the previous studies: striped dolphins had the greatest number of encounters and largest group sizes in offshore warm waters $>18^{\circ} \mathrm{C}$ (Becker 2007, Becker et al. 2010), Dall's porpoise had the greatest number of encounters in cooler, upwellingmodified water $<17^{\circ} \mathrm{C}$ (Forney 2000, Becker 2007, Becker et al. 2010), and fin whales had the greatest number of encounters in moderate-temperature waters of $14-19^{\circ} \mathrm{C}$ (Becker 2007, Becker et al. 2010) (Fig. 4). The explained deviance ranged from 8.6 (fin whale) to $34.2 \%$ (Dall's porpoise) for the encounter rate models, and from 5.1 (fin whale) to $16.7 \%$ (striped dolphin) for the group size models (Table 1).

\section{Nowcast predictions}

Relative density predictions using daily blended SST matched to each survey day and time for the entire 2008 survey showed good concordance be-

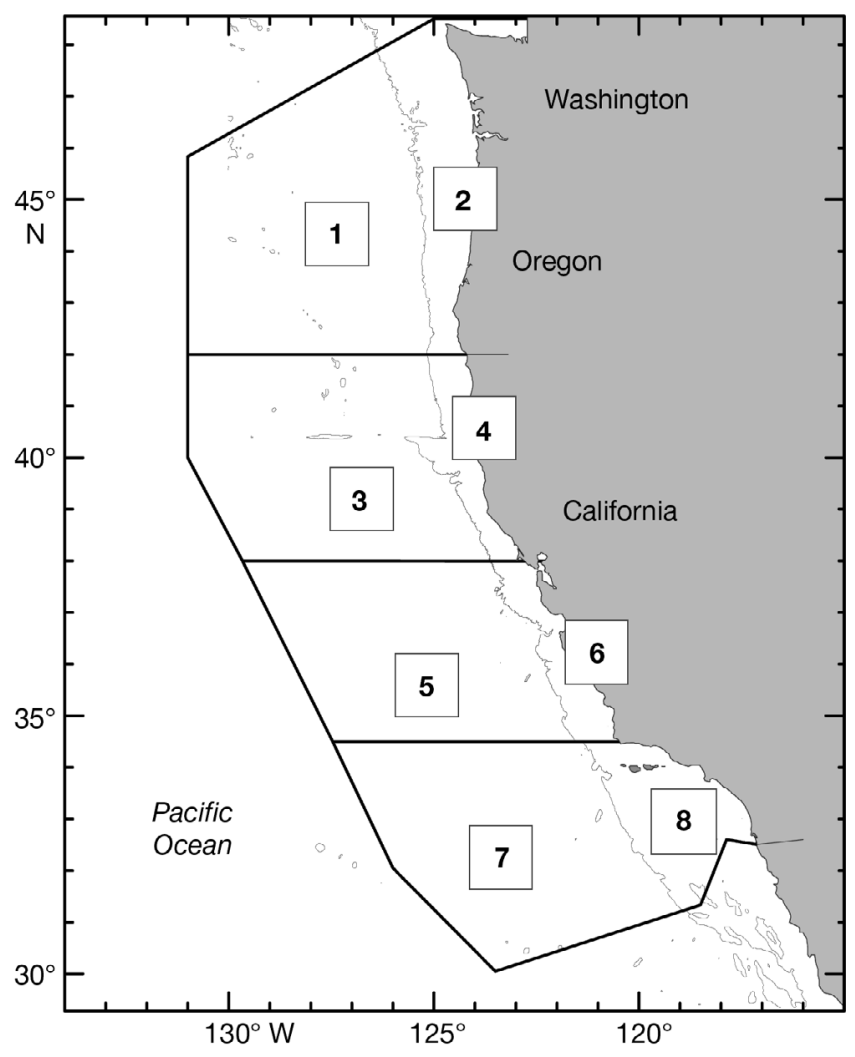

Fig. 3. Geographic strata used for the Spearman rank correlation tests: the 4 north-south strata are consistent with those used for line-transect abundance estimation (Barlow \& Forney 2007) and an offshore-onshore division occurs at the $2000 \mathrm{~m}$ isobath

Table 1. Percentage of deviance explained by the final 1991-2005 encounter rate and group size models for each species

\begin{tabular}{|lccc|}
\hline $\begin{array}{l}\text { Common } \\
\text { name }\end{array}$ & $\begin{array}{c}\text { Scientific } \\
\text { name }\end{array}$ & $\begin{array}{c}\text { Encounter } \\
\text { rate model (\%) }\end{array}$ & $\begin{array}{c}\text { Group size } \\
\text { model (\%) }\end{array}$ \\
\hline $\begin{array}{c}\text { Striped } \\
\text { dolphin }\end{array}$ & $\begin{array}{c}\text { Stenella } \\
\text { coeruleoalba }\end{array}$ & 9.6 & 16.7 \\
$\begin{array}{c}\text { Dall's } \\
\text { porpoise }\end{array}$ & $\begin{array}{c}\text { Phocoenoides } \\
\text { dalli }\end{array}$ & 34.2 & 10.7 \\
$\begin{array}{c}\text { Fin } \\
\text { whale }\end{array}$ & $\begin{array}{c}\text { Balaenoptera } \\
\text { physalus }\end{array}$ & 8.6 & 5.1 \\
\hline
\end{tabular}

tween observed sighting locations and model predictions, and were more accurate at identifying subtle differences in distributions at finer scales than the average model predictions (Fig. 5). For example, the relative density predictions for striped dolphins based on daily blended SST matched the 2008 sighting data better than predictions from the average models, particularly in the southwestern portion of 


\section{a Striped dolphin}
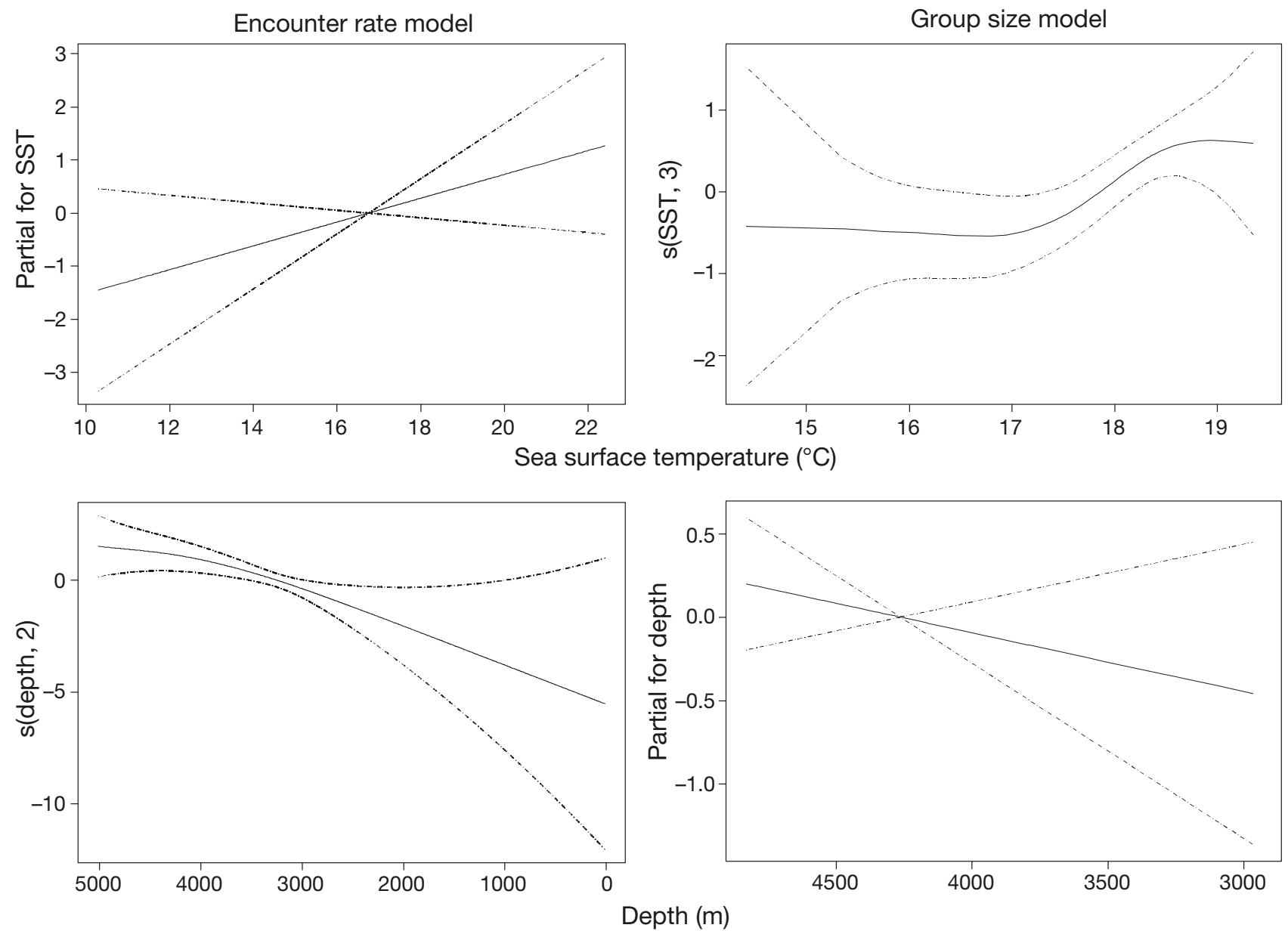

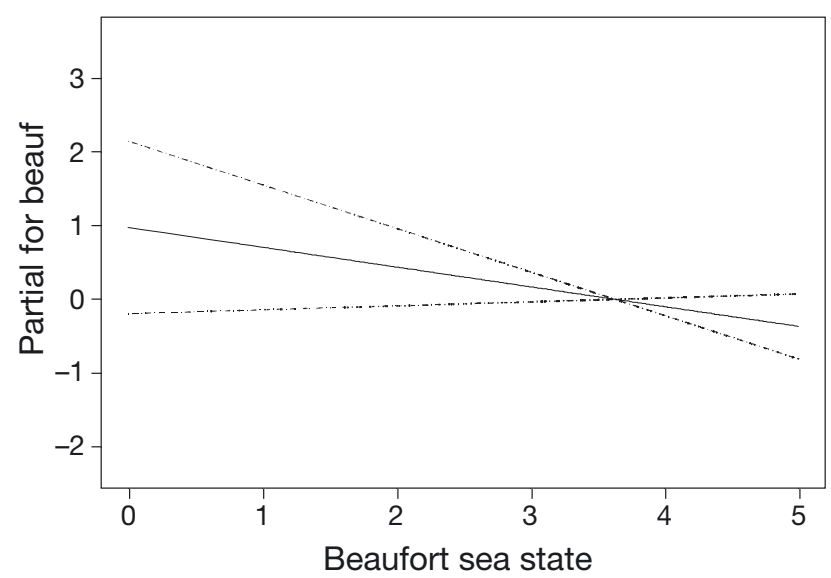

the study area where, based on the actual 2008 sighting data, relative density was lower than the 19912005 average (Fig. 5a). Compared with the 19912005 average, the 2008 distribution of Dall's porpoise shifted south into central and northern California waters and this shift was picked up effectively by the
Fig. 4. Encounter rate and group size model functions for (a) striped dolphin, (b) Dall's porpoise and (c) fin whale. Models were constructed with both linear terms and smoothing splines ('s' on the $y$-axis) having up to 3 degrees of freedom. Degrees of freedom for nonlinear fits are in parentheses on the $y$-axis. Potential predictor variables included sea surface temperature (SST), water depth, bathymetric slope and Beaufort (beauf) sea state (the groupsize model did not include Beaufort sea state). The $y$-axes represent the term's (linear or spline) function. Zero on the $y$-axes corresponds to no effect of the predictor variable on the estimated response variable (encounter rate or group size). The scaling of the $y$-axes varies among predictor variables to emphasize model fit. Dashed lines: $95 \%$ confidence intervals

(continued on following 2 pages)

nowcast model predictions (Fig. 5b). Nowcast predictions were also able to identify the higher numbers of fin whales in the northwest portion of our study area, as well as the lower numbers off northern California between $38^{\circ} \mathrm{N}$ and $40^{\circ} \mathrm{N}$ that were missed by the average models (Fig. 5c). 


\section{b Dall's porpoise}
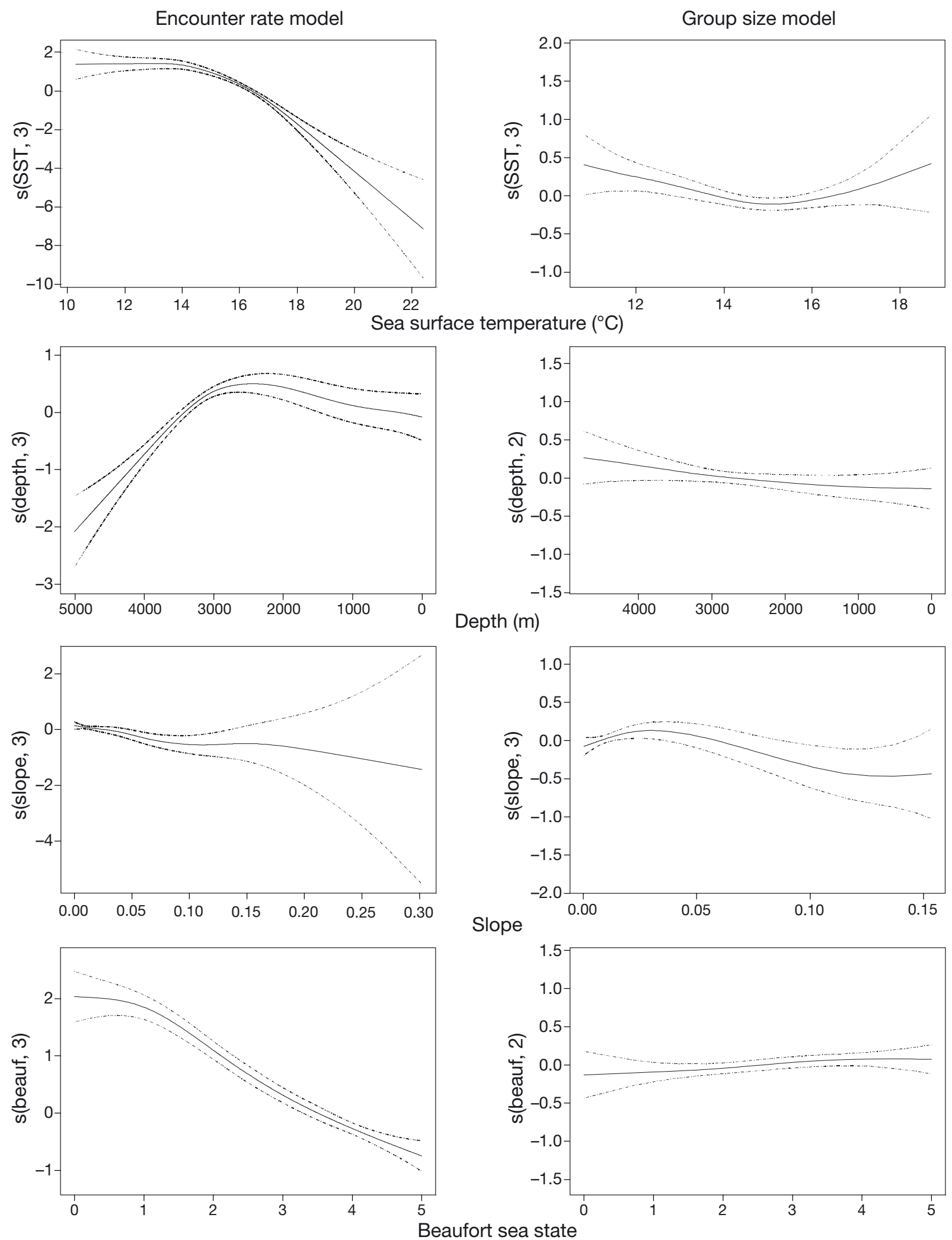

Fig. 4 (continued) 
c Fin whale

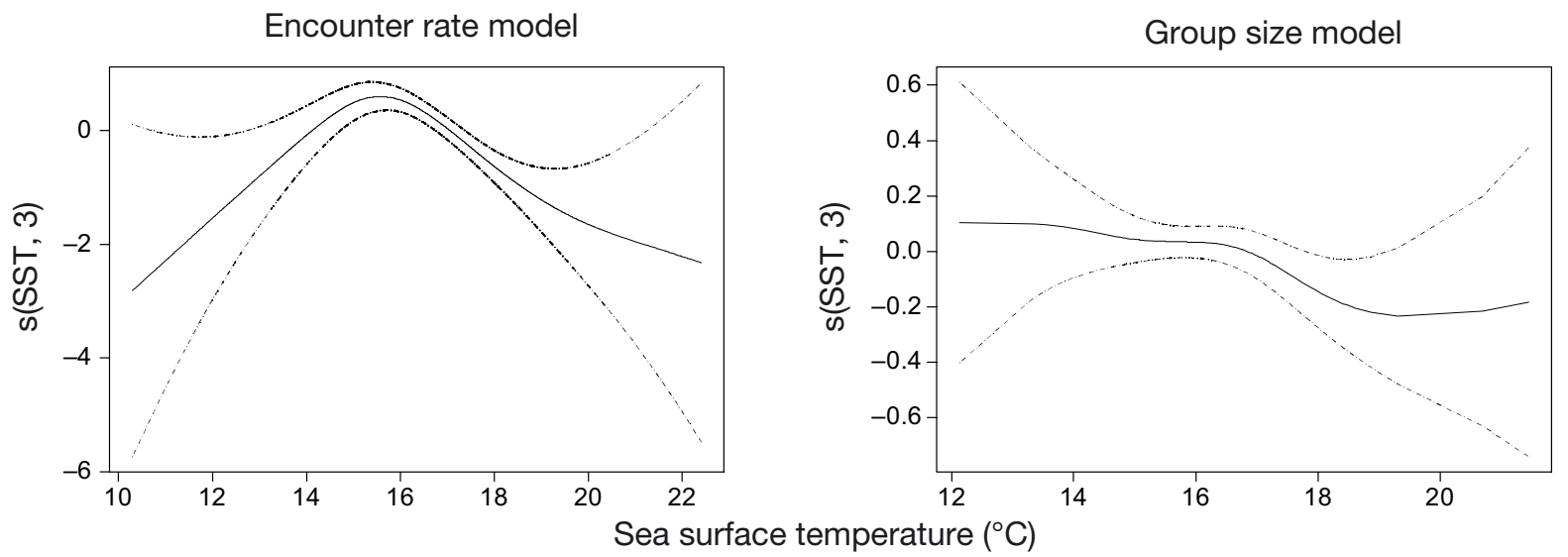

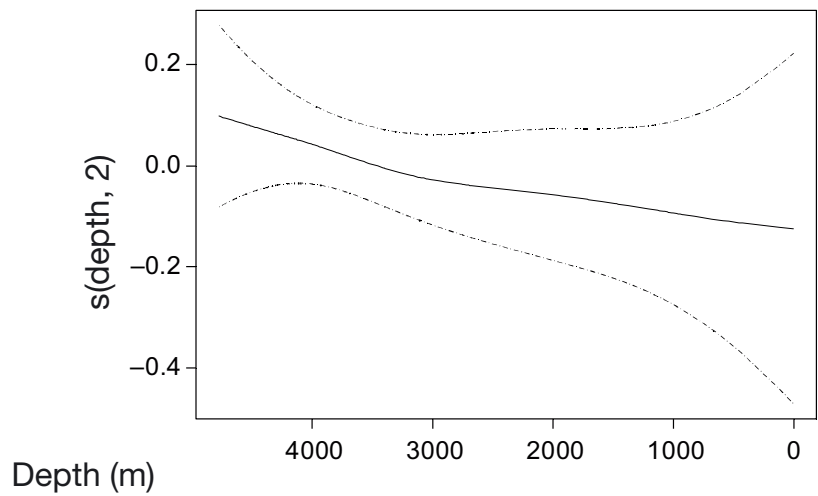
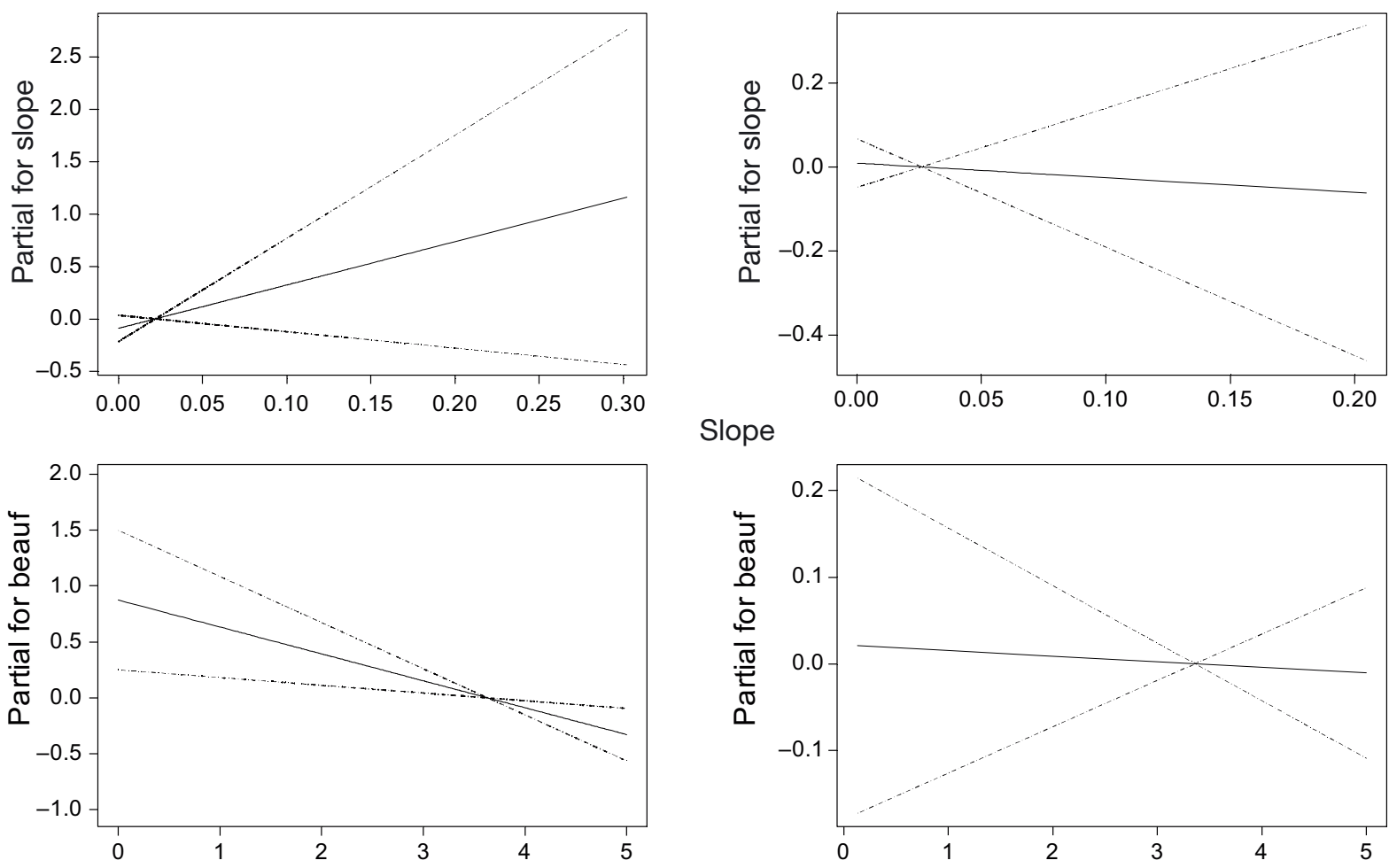

Slope

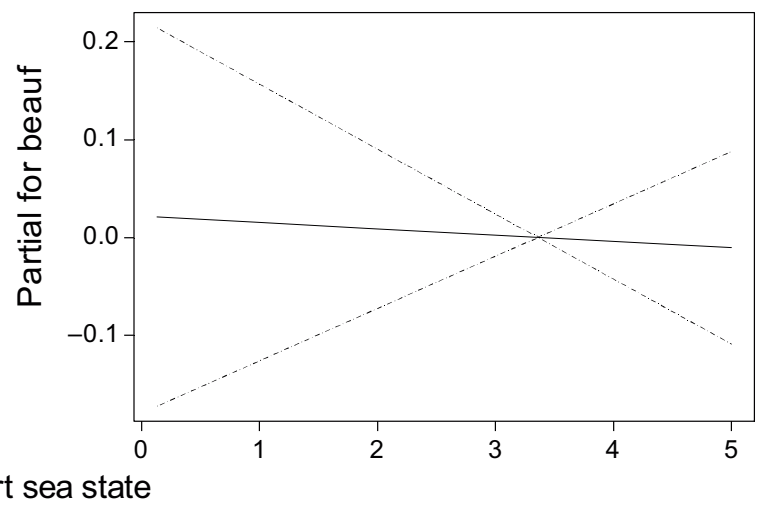

Fig. 4 (continued) 

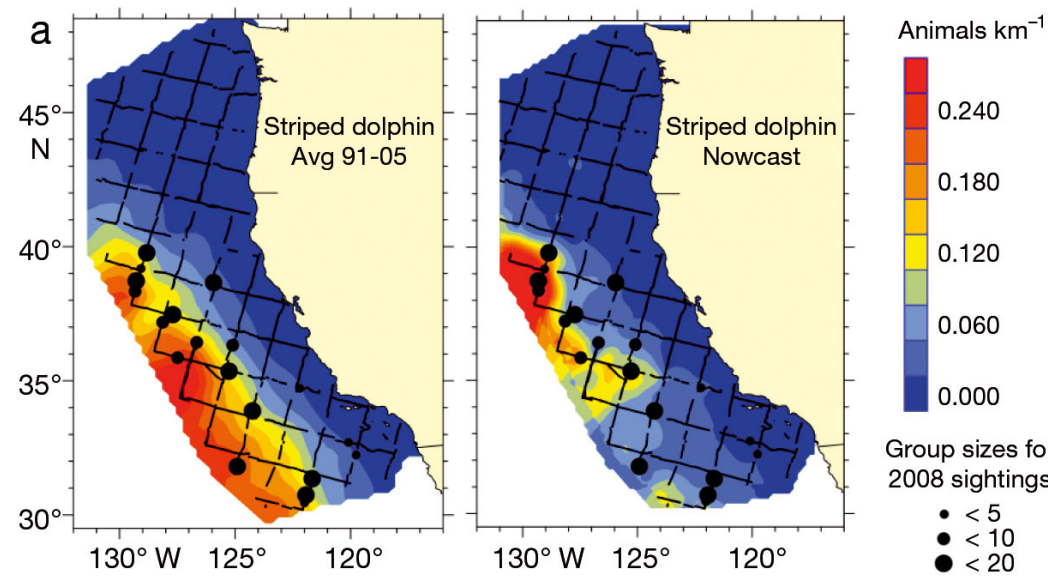

Group sizes for 2008 sightings

- $<5$

$<10$

$<20$
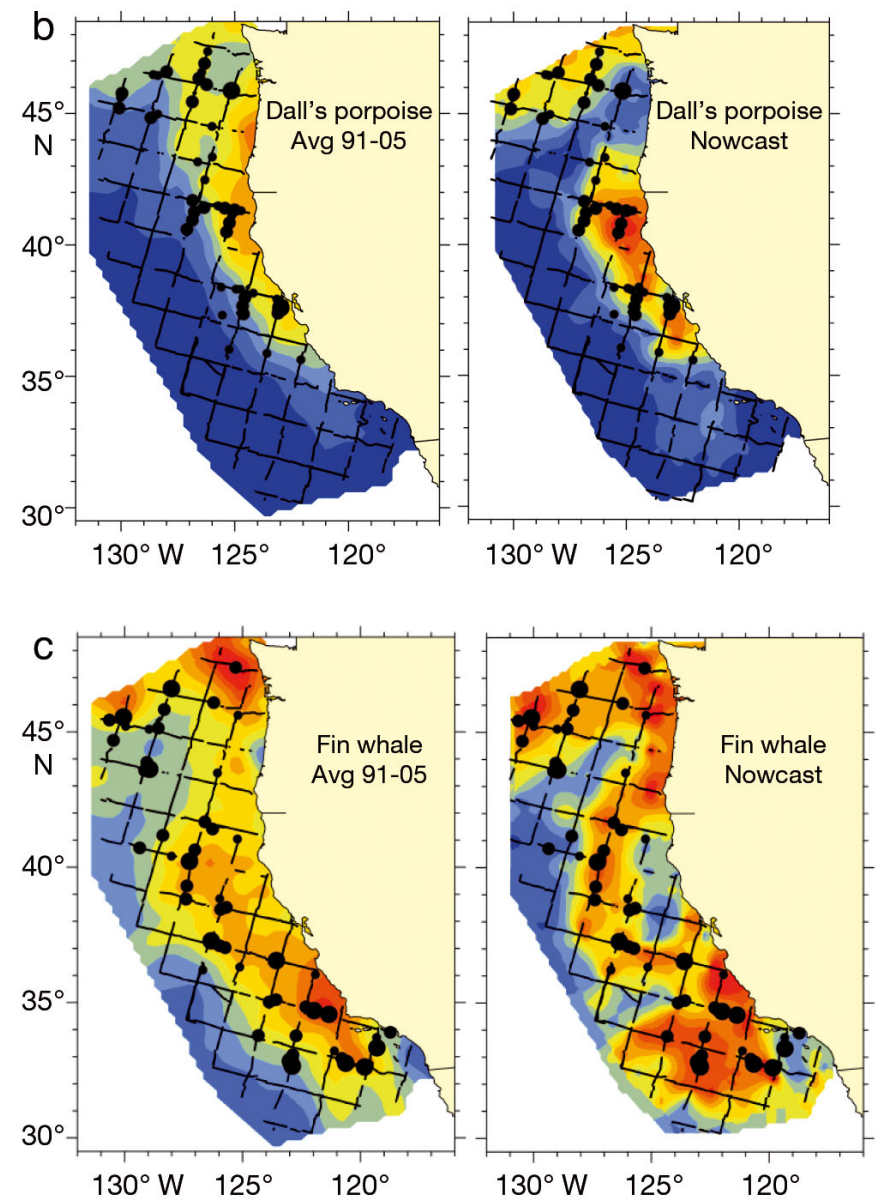

For all 3 species, the relative density estimates derived from the nowcast model for the entire study area for 2008 were similar to those estimated directly from the survey data and, for striped dolphin and fin whale, were much closer to the survey estimates than the average model predictions (see ratios in Table 2). Although the survey estimates are not necessarily unbiased, in concert with line-transect correction factors (Buckland et al. 2001), they are currently the standard measure used to estimate cetacean abundance. Coefficients of variation (CVs) associated with recent line-transect abundance estimates for the 3 species derived from the 1991-2005 survey data used to build the models in this study ranged from 18 to $45 \%$ for the entire study area (Barlow \& Forney 2007). The relative density ratios (line transect over model-predicted) for the nowcast models are within the range of these $\mathrm{CVs}$, as all the nowcast estimates are within a factor of approximately 2 from the survey estimates (Table 2). The survey-based 2008 relative density estimate for striped dolphin was lower than in past years, whereas the relative density of fin whale was estimated to be greater in 2008; both of these changes were effectively captured by the nowcast models.

The rank correlation test results for the nowcast models are in good agreement with our visual evaluations; for all 3 species, Spearman rank correlation coefficients were significant $(p<0.05$; Table 3$)$, indicating that the predicted ranks across geographic strata matched well with the relative abundance ranks estimated from the observed data. These results suggest that the nowcast models built with data from past years were able to capture spatial patterns of abundance for all 3 species during 2008 by using novel satellite-derived oceanographic data for 2008 as predictor variables.
Fig. 5. Predicted relative density estimates for (a) striped dolphin, (b) Dall's porpoise and (c) fin whale based on average model predictions for 1991-2005 and blended sea surface temperature values matched to each day and time of the 2008 survey (Nowcast). Predictions are shown for the study area (Fig. 2). Interpolation grids were created at a resolution of $25 \mathrm{~km}$, using inverse distance weighting to the second power in Surfer software (Version 9). The same species-specific relative density scale was used to enable a comparison between the predictions. Black dots show actual 2008 sighting locations, with the size of the dot representing species-specific group sizes (larger dots indicate larger observed group sizes). Black lines show actual effort for the entire 2008 survey 
Table 2. Survey data and model-predicted 2008 encounter rate (group encounters per $\mathrm{km}$ ), average group size and relative density (total animals per $\mathrm{km}$, calculated as encounter rate $\times$ group size) estimates for the entire study area. Ratios represent line-transect over model-predicted relative density estimates. The model with the ratio closest to 1.00 appears in bold to illustrate the model that is most similar to the 2008 survey data. For taxonomic names, see Table 1

\begin{tabular}{|c|c|c|c|c|c|}
\hline \multirow[t]{2}{*}{ Parameter } & \multicolumn{3}{|c|}{ Model-predicted estimate } & \multicolumn{2}{|c|}{ Ratio -} \\
\hline & $\begin{array}{l}\text { Survey } \\
\text { estimate }\end{array}$ & $\begin{array}{c}\text { Average } \\
(1991-2005)\end{array}$ & Nowcast & $\begin{array}{c}\text { Average } \\
(1991-2005)\end{array}$ & Nowcast \\
\hline \multicolumn{6}{|l|}{ Striped dolphin } \\
\hline Encounter rate & 0.0016 & 0.0016 & 0.0013 & & \\
\hline Group size & 9.55 & 31.77 & 25.72 & & \\
\hline Relative density & 0.0153 & 0.0508 & 0.0334 & 0.30 & 0.46 \\
\hline \multicolumn{6}{|l|}{ Dall's porpoise } \\
\hline Encounter rate & 0.0061 & 0.0044 & 0.0057 & & \\
\hline Group size & 3.36 & 5.41 & 4.47 & & \\
\hline Relative density & 0.0205 & 0.0239 & 0.0253 & 0.86 & 0.81 \\
\hline \multicolumn{6}{|l|}{ Fin whale } \\
\hline Encounter rate & 0.0066 & 0.0048 & 0.0054 & & \\
\hline Group size & 2.58 & 1.84 & 1.90 & & \\
\hline Relative density & 0.0170 & 0.0088 & 0.0103 & 1.93 & 1.65 \\
\hline
\end{tabular}

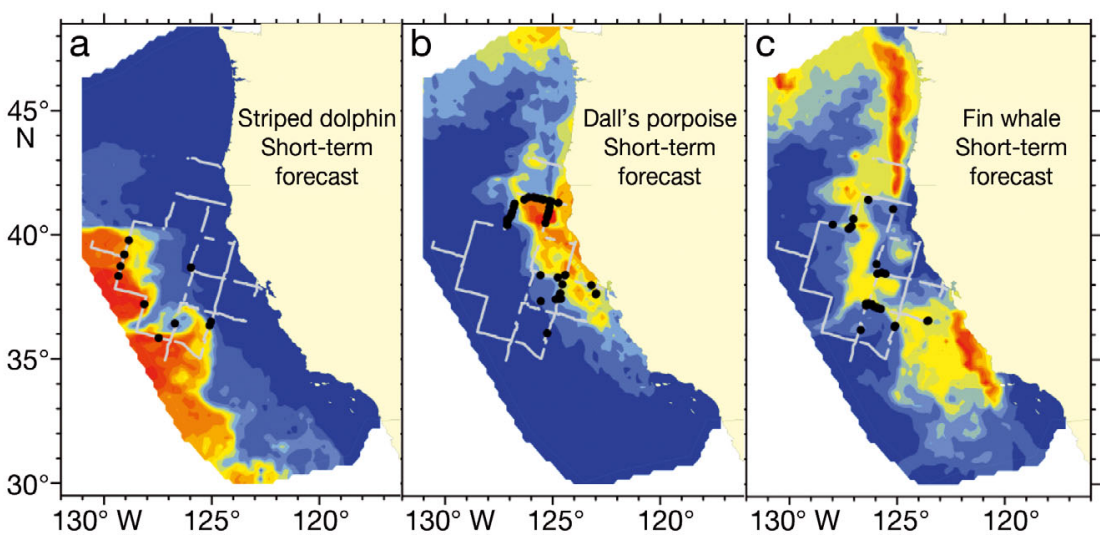

Fig. 6. Predicted relative density estimates for (a) striped dolphin, (b) Dall's porpoise and (c) fin whale based on blended sea surface temperature values for 1 September 2008. Predictions are shown for the study area (Fig. 2). Interpolation grids were created at a resolution of $25 \mathrm{~km}$, using inverse distance weighting to the second power in Surfer software (Version 9). Red and orange represent the highest predicted density, yellow and green moderate density, and blue the lowest density. Black dots show actual sighting locations for the month of September from the 2008 survey; white lines show actual effort for the month of September from the 2008 survey

\section{Short-term forecast predictions}

Relative density predictions using a single day of blended SST were in good agreement with actual observations during the subsequent month for all 3 species (Fig. 6). The transect lines completed during September of the 2008 survey extended from the coast to the western limit of the study area, enabling a comparison of the general distribution patterns among the 3 species. As is evident from both the observed sighting locations and the short-term relative density predictions, striped dolphins were found mainly in the western portion of the study area, Dall's porpoises closest to the coast and fin whales generally in between the two (Fig. 6).

\section{Medium-term forecast predictions}

The sighting locations of striped dolphin, Dall's porpoise and fin whale during October and November of the 2008 survey were visually concordant with 3-4 mo model forecast predictions based on the ROMS monthly SST values (Fig. 7). Although survey effort was concentrated in the southern portion of the study area during these 2 months, in general there were sightings in areas where relative density was predicted to be moderate to high, and few to no sightings in areas predicted to have the lowest relative density.

Forecast estimates of relative density for the portions of the study area surveyed in October and November 2008 were closer to the survey-based estimates than the average models for all 3 species (Table 4). With the exception of Dall's porpoise, for which there were few sightings in October and none in November, the forecast estimates were within a factor of approximately 2 from the survey estimates, and compared favorably with the CVs associated with recent linetransect abundance estimates for 4 geographically stratified regions of our study area (CVs ranged from 26 to $>100 \%$; Barlow \& Forney 2007). The October forecast estimate for Dall's porpoise was greater than a factor of 4 from the survey estimate; however, it was closer than that of the average model. The 3 mo predictions more accurately identified the relatively lower density of striped dolphin and relatively higher density of fin whale in the October 2008 survey area than would be assumed from the average model pre- 
Table 3. Summary of Spearman rank correlation coefficients for the 2 models, Average (1991-2005) and Nowcast. The critical value at $\alpha=0.05$ (1-tailed test) with 5 degrees of freedom is $r_{\text {crit }}=0.643$ (i.e. values are significant if larger); thus all correlations are significant. For taxonomic names, see Table 1

\begin{tabular}{|lcc|}
\hline Species & \multicolumn{2}{c|}{$\mathrm{r}$ Nowage } \\
\cline { 2 - 3 }$(1991-2005)$ & \\
\hline Striped dolphin & 0.850 & 0.875 \\
Dall's porpoise & 0.778 & 0.766 \\
Fin whale & 0.810 & 0.905 \\
\hline
\end{tabular}

dictions. Although the differences were not as great, the 4 mo predictions were also able to more effectively capture the numbers of animals observed during the November 2008 survey compared with the average model predictions. The fin whale relative density forecast was remarkably good, with an observed to predicted ratio that approached $1(0.99$; Table 4).

\section{DISCUSSION}

Our ability to assess potential impacts on cetacean species from anthropogenic activities within specific areas of the CCE have been based on uniformdensity estimates from broad-scale line-transect surveys and, more recently, from finer-scale habitatbased estimates of cetacean density (see Forney et al. 2012). The habitat-based density models are developed from systematic line-transect survey data collected during previous years, and unless someone is surveying an area in real time, these model predictions currently provide our best expectation of current and future species distribution patterns. However, the CCE is a highly dynamic ecosystem, and in any given year, patterns of cetacean distribution and abundance can be markedly different from the average or another single year.

This case study demonstrates that satellite-derived and modeled oceanic SST data can be successfully used as input variables in models developed using survey data to provide nowcast and forecast predictions of relative density for 3 CCE cetacean species. Model predictions based on a single daily blended SST image demonstrated not only nowcast ability, but reasonable 2-4 wk forecast ability as well, suggesting that this could be an effective tool for resource managers who require near real-time predictions of cetacean distribution to avoid or mitigate adverse impacts. However, results may differ among
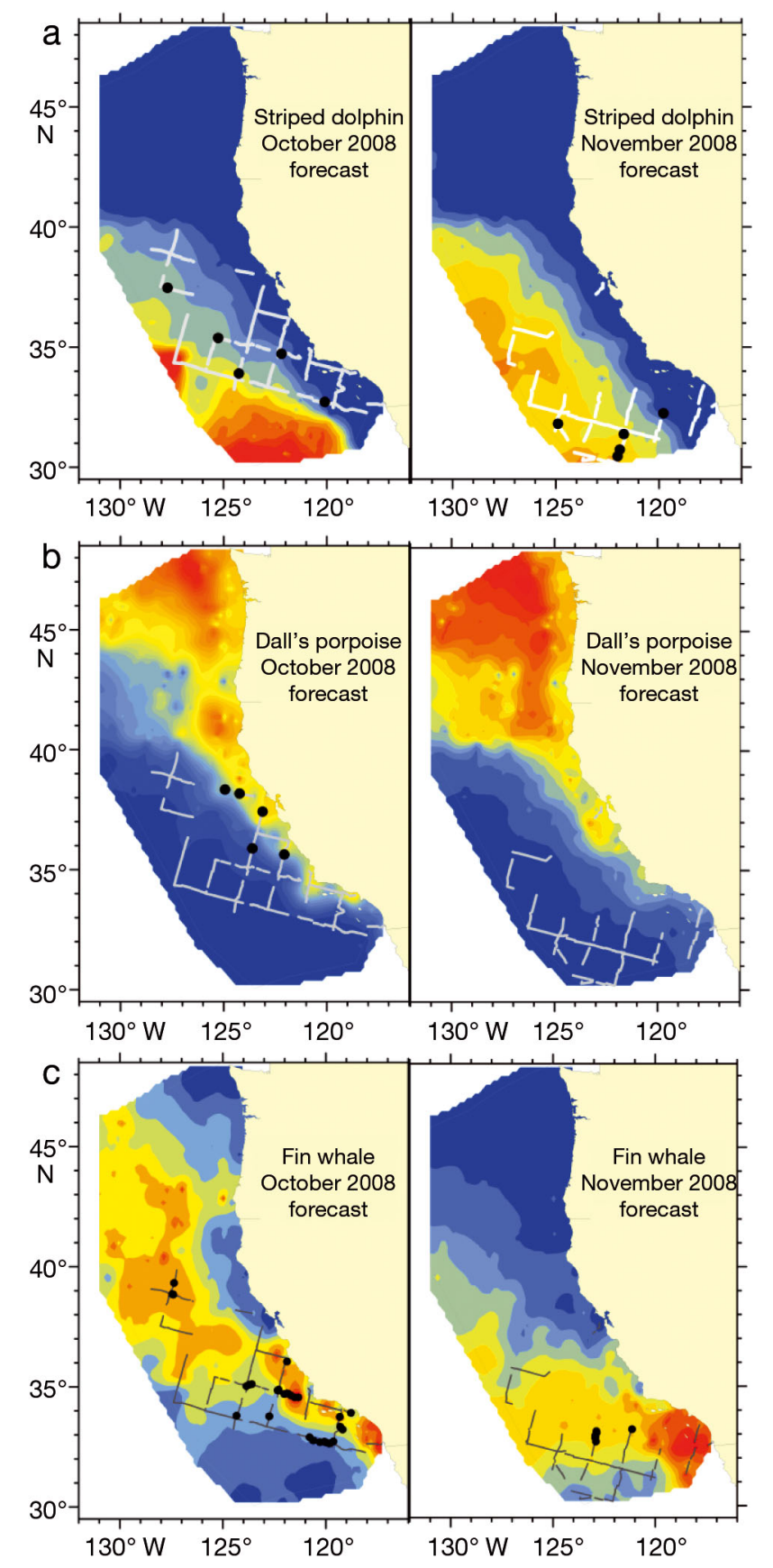

Fig. 7. Predicted relative density estimates for (a) striped dolphin, (b) Dall's porpoise and (c) fin whale based on July 2008 Regional Ocean Modeling System monthly sea surface temperature predictions for October and November 2008. Predictions are shown for the study area (Fig. 2). Interpolation grids were created at a resolution of $25 \mathrm{~km}$, using inverse distance weighting to the second power in Surfer software (Version 9). Red and orange represent highest predicted density, yellow and green moderate density, and blue the lowest density. Black dots show actual sighting locations for October and November from the 2008 survey; white (striped dolphin and Dall's porpoise) and black (fin whale) lines show actual effort for October and November from the 2008 survey 
Table 4. Survey data and model-predicted 2008 encounter rate (group encounters per $\mathrm{km}$ ), average group size and relative density (total animals per $\mathrm{km}$, calculated as encounter rate $\times$ group size) estimates for the portions of the study area surveyed in October and November 2008 (survey tracklines are depicted in Fig. 7). Ratios represent line-transect over model-predicted relative density estimates. The model with the ratio closest to 1.00 appears in bold to illustrate the model that is most similar to the 2008 survey data. For taxonomic names, see Table 1

\begin{tabular}{|c|c|c|c|c|c|}
\hline \multirow[t]{2}{*}{ Parameter } & \multicolumn{3}{|c|}{ Model-predicted estimate } & \multicolumn{2}{|c|}{ Ratio } \\
\hline & $\begin{array}{c}\text { Survey } \\
\text { estimate }\end{array}$ & $\begin{array}{c}\text { Average } \\
(1991-2005)\end{array}$ & Forecast & $\begin{array}{c}\text { Average } \\
(1991-2005)\end{array}$ & Forecast \\
\hline \multicolumn{6}{|l|}{ October } \\
\hline \multicolumn{6}{|l|}{ Striped dolphin } \\
\hline Encounter rate & 0.0016 & 0.0018 & 0.0016 & & \\
\hline Group size & 11.23 & 37.35 & 24.04 & & \\
\hline Relative density & 0.0180 & 0.0672 & 0.0385 & 0.27 & 0.47 \\
\hline \multicolumn{6}{|l|}{ Dall's porpoise } \\
\hline Encounter rate & 0.0012 & 0.0042 & 0.0042 & & \\
\hline Group size & 3.58 & 5.68 & 4.45 & & \\
\hline Relative density & 0.0043 & 0.0241 & 0.0189 & 0.18 & 0.23 \\
\hline \multicolumn{6}{|l|}{ Fin whale } \\
\hline Encounter rate & 0.0084 & 0.0041 & 0.0060 & & \\
\hline Group size & 2.44 & 1.81 & 1.92 & & \\
\hline Relative density & 0.0205 & 0.0074 & 0.0115 & 2.77 & 1.78 \\
\hline \multicolumn{6}{|l|}{ November } \\
\hline \multicolumn{6}{|l|}{ Striped dolphin } \\
\hline Encounter rate & 0.0023 & 0.0017 & 0.0017 & & \\
\hline Group size & 9.43 & 28.99 & 24.13 & & \\
\hline Relative density & 0.0217 & 0.0493 & 0.0410 & 0.44 & 0.53 \\
\hline \multicolumn{6}{|l|}{ Dall's porpoise } \\
\hline Encounter rate & $0^{\mathrm{a}}$ & 0.0044 & 0.0027 & & \\
\hline Group size & $0^{\mathrm{a}}$ & 5.09 & 4.40 & & \\
\hline Relative density & $0^{\mathrm{a}}$ & 0.0223 & 0.0118 & - & - \\
\hline \multicolumn{6}{|l|}{ Fin whale } \\
\hline Encounter rate & 0.0032 & 0.0056 & 0.0067 & & \\
\hline Group size & 4.16 & 1.94 & 2.00 & & \\
\hline Relative density & 0.0133 & 0.0109 & 0.0134 & 1.33 & 0.99 \\
\hline
\end{tabular}

other ecosystems and environmental predictors; in general, the effectiveness of nowcast predictions will be a function of how dynamic the ecosystem and predictor are, how well the models capture the underlying variability and whether there is a temporal lag in the predictor. For example, time lags may be important for some variables, such as chlorophyll concentration (Jaquet et al. 1996).

The demonstrated refinement of the temporal predictions using daily blended SST suggests that we can make reasonable predictions of relative density for species with strong SST relationships without having to collect real-time in situ data. Such predictions would not be possible without recent advance- ments in processing multi-sensor satellite-derived data that have virtually eliminated the cloud cover issue for SST. This shows promise for both scientists and resource managers as it provides a prediction tool for periods we have not surveyed. However, care should be taken when making predictions beyond the range at which the habitat variables were measured. For example, when evaluating the ability of habitat-based density models to predict across seasons, Becker (2007) found that models produced unrealistic values when applied to data outside of the range used to build the models. In addition, it will be difficult to predict abundance if the animals' behavioral state (e.g. foraging, migrating and breeding) changes. For example, the environmental variables used for modeling will not reflect the absence of species that move to different areas for seasonal breeding. Further, the habitatbased density models are built based on a contemporary population abundance, so forecasts should not be made so far in the future that they are forecasting outside of the 'population space' from which the models were developed. Underlying trends in abundance may change the relationships among cetacean distribution and their environment, e.g. as a previously exploited population recovers and moves back into areas that were not used at low population sizes.

As satellite-derived and modeled oceanic SST data are generally available for all grid cells, spatial predictions can be made over an entire study area, unlike in situ data that are limited by the areas surveyed. Species-specific $f(0)$ and $g(0)$ values suitable for model inclusion should be derived in the future to allow models to nowcast and forecast actual densities or numbers of animals within an area. Further analyses should also examine model predictions at finer scales than were possible in this study given the limited number of sightings available from our 2008 validation survey. Currently, the resolution of the predicted relative density estimates are too coarse to evaluate small-scale changes that would be useful in evaluating alternative shipping routes for whale- 
vessel interactions (Redfern et al. unpubl. data) or navy testing and training operations that occur in specified operational areas (Department of the Navy 2008). Evaluating the ability of coarse-scale models to predict finer-scale density estimates would be beneficial, as would additional finer-scale surveys.

The success of the SST-based nowcast and forecast predictions demonstrated by this case study provides a foundation for other habitat modeling efforts. Other cetacean species, however, require more complex habitat models that include predictor variables such as chlorophyll, salinity, mixed layer depth and zooplankton indices (Redfern et al. 2008, Barlow et al. 2009). Accessibility to the output of ROMS and similar oceanic models is increasing rapidly, providing forecasts of relevant oceanographic parameters. Their use as predictors can be expected to improve the models' nowcast and forecast ability, and might also prove to be useful for evaluating historic changes in cetacean abundance and distribution (i.e. hindcasts), as well as changes that may occur under a number of projected climate change scenarios. The ability to produce even short-term forecast predictions would significantly improve the capability of resource managers to analyze and make decisions related to protected species abundance and distribution. For example, the ability to forecast densities, particularly at finer spatial scales, could help the Navy select the lowest impact areas for testing and training activities (Department of the Navy 2010), aid in the identification of overlap between large whales and shipping traffic (Redfern et al. unpubl. data), and provide a basis for adaptive surveys or sampling design as effort could be concentrated in areas predicted to have greater abundance.

Acknowledgements. We are very grateful to everyone involved in the collection of the data used in our analyses, including the marine mammal observers, oceanographers, cruise leaders, cruise coordinators, officers and crew of the RVs 'David Starr Jordan', 'McArthur' and 'McArthur II'. S. Reilly, L. Ballance and G. Watters served as Ecosystem Program leaders during the shipboard surveys. This manuscript was improved by the careful reviews of M. Ferguson, R. Smith and 3 anonymous reviewers. Funding for this study was provided by the National Aeronautics and Space Administration (NASA) under grant/cooperative agreement number NNX08AK736, NASA agreement number NNX09AI88G and the Southwest Fisheries Science Center.

\section{LITERATURE CITED}

Akaike H (1973) Information theory and an extension of the maximum likelihood principle. In: Petran BN, Csàaki $F$ (eds) Second International Symposium on Information Theory. Akadèemiai Kiadi, Budapest, p 267-281
Barlow J, Forney KA (2007) Abundance and density of cetaceans in the California Current ecosystem. Fish Bull 105:509-526

Barlow J, Gerrodette T, Forcada J (2001) Factors affecting perpendicular sighting distances on shipboard linetransect surveys for cetaceans. J Cetacean Res Manag 3: 201-212

Barlow J, Ferguson MC, Becker EA, Redfern JV and others (2009) Predictive modeling of cetacean densities in the eastern Pacific Ocean. NOAA Tech Memo NMFSSWFSC-444

Baumgartner MF, Mate BR (2003) Summertime foraging ecology of North Atlantic right whales. Mar Ecol Prog Ser 264:123-135

> Baumgartner MF, Cole TVN, Clapham PJ, Mate BR (2003) North Atlantic right whale habitat in the lower Bay of Fundy and on the SW Scotian Shelf during 1999-2001. Mar Ecol Prog Ser 264:137-154

Becker EA (2007) Predicting seasonal patterns of California cetacean density based on remotely sensed environmental data. PhD dissertation, University of California, Santa Barbara, CA

> Becker EA, Forney KA, Ferguson MC, Foley DG, Smith RC, Barlow J, Redfern JV (2010) Comparing California Current cetacean-habitat models developed using in situ and remotely sensed sea surface temperature data. Mar Ecol Prog Ser 413:163-183

Buckland ST, Anderson DR, Burnham KP, Laake JL, Borchers DL, Thomas L (2001) Introduction to distance sampling: estimating abundance of biological populations. Oxford University Press, Oxford

Cañadas A, Sagarminaga R, García-Tiscar S (2002) Cetacean distribution related with depth and slope in the Mediterranean waters off southern Spain. Deep-Sea Res I 49:2053-2073

Chao Y, Li Z, Farrara J, McWilliams JC and others (2009) Development, implementation and evaluation of a dataassimilative ocean forecasting system off the central California coast. Deep-Sea Res II 56:100-126

> Chavez FP, Ryan J, Lluch-Cota SE, Niquen CM (2003) From anchovies to sardines and back: multidecadal change in the Pacific Ocean. Science 299:217-221

> Croll DA, Marinovic B, Benson S, Chavez FP, Black N, Ternullo R, Tershy BR (2005) From wind to whales: trophic links in a coastal upwelling system. Mar Ecol Prog Ser 289:117-130

Department of the Navy (2008) Final environmental impact statement/overseas environmental impact statement for the Southern California Range Complex. Pacific Fleet Environmental Office, San Diego, CA

Department of the Navy (2010) Final environmental impact statement/overseas environmental impact statement for the Northwest Training Range Complex. Pacific Fleet Environmental Office, Silverdale, WA

Edwards EF, Perkins PC (1992) Power to detect linear trends in dolphin abundance: estimates from tuna-vessel observer data, 1975-89. Fish Bull 90:625-631

Ferguson MC, Barlow J, Fiedler P, Reilly SB, Gerrodette T (2006) Spatial models of delphinid (family Delphinidae) encounter rate and group size in the eastern tropical Pacific Ocean. Ecol Model 193:645-662

Forney KA (1999) Trends in harbor porpoise abundance off central California, 1986-95; evidence for interannual change in distribution? J Cetacean Res Manag 1: $73-80$ 
Forney KA (2000) Environmental models of cetacean abundance: reducing uncertainty in population trends. Conserv Biol 14:1271-1286

Forney KA, Hanan DA, Barlow J (1991) Detecting trends in harbor porpoise abundance from aerial surveys using analysis of covariance. Fish Bull 89:367-377

Forney KA, Ferguson MC, Becker EA, Fiedler PC and others (2012) Habitat-based spatial models of cetacean density in the eastern Pacific Ocean. Endang Species Res 16: 113-133

Gaskin DE (1987) Updated status of the right whale, Eubalaena glacialis, in Canada. Can Field Nat 101:295-309

Gentemann CL, Minnett PJ, Sienkiewicz J, DeMaria M and others (2009) The Multi-sensor Improved Sea Surface Temperature (MISST) project. Oceanography 22:76-87

Hastie TJ, Tibshirani RJ (1990) Generalized additive models, Vol. 43. Chapman \& Hall/CRC, Boca Raton, FL

Hedley SL, Buckland ST, Borchers DL (1999) Spatial modelling from line transect data. J Cetacean Res Manag 1: 255-264

Hooker SK, Whitehead H, Gowans S (1999) Marine protected area design and the spatial and temporal distribution of cetaceans in a submarine canyon. Conserv Biol 13:592-602

> Jaquet N, Whitehead H, Lewis M (1996) Coherence between 19th century sperm whale distributions and satellite-derived pigments in the tropical Pacific. Mar Ecol Prog Ser 145:1-10

Kaschner K, Watson R, Trites AW, Pauly D (2006) Mapping world-wide distributions of marine mammal species using a relative environmental suitability (RES) model. Mar Ecol Prog Ser 316:285-310

Kinzey D, Olson P, Gerrodette T (2000) Marine mammal data collection procedures on research ship line-transect surveys by the Southwest Fisheries Science Center. Report No. LJ-00-08, Southwest Fisheries Science Center, La Jolla, CA

Koslow JA, Hobday AJ, Boehlert GW (2002) Climate variability and marine survival of coho salmon (Oncorhynchus kisutch) in the Oregon production area. Fish Oceanogr 11:65-77

Maravelias CD, Reid DG, Swartzman G (2000) Modelling spatio-temporal effects of environment on Atlantic herring, Clupea harengus. Environ Biol Fishes 58:157-172

Editorial responsibility: Mark Baumgartner, Woods Hole, Massachusetts, USA
Murison LD, Gaskin DE (1989) The distribution of right whales and zooplankton in the Bay of Fundy, Canada. Can J Zool 67:1411-1420

Peterman RM, Bradford MJ (1987) Statistical power of trends in fish abundance. Can J Fish Aquat Sci 47:2-15

Pyper BJ, Peterman RM (1999) Relationship among adult body length, abundance, and ocean temperature for British Columbia and Alaska sockeye salmon (Oncorhynchus nerka), 1967-1997. Can J Fish Aquat Sci 56: 1716-1720

Ralls K, Taylor BL (2000) Better policy and management decisions through explicit analysis of uncertainty: new approaches from marine conservation. Conserv Biol 14: 1240-1242

> Redfern JV, Barlow J, Ballance LT, Gerrodette T, Becker EA (2008) Absence of scale dependence in dolphin-habitat models for the eastern tropical Pacific Ocean. Mar Ecol Prog Ser 363:1-14

Reynolds RW, Smith TM (1994) Improved global sea surface temperature analyses using optimum interpolation. J Clim 7:929-948

Roemmich D, McGowan J (1995) Climatic warming and the decline of zooplankton in the California Current. Science 267:1324-1326

Rosenkranz GE, Tyler AV, Kruse GH (2001) Effects of water temperature and wind on year-class success of Tanner crabs in Bristol Bay, Alaska. Fish Oceanogr 10:1-12

> Taylor BL, Gerrodette T (1993) The uses of statistical power in conservation biology: the vaquita and the spotted owl. Conserv Biol 7:489-500

Torres LG, Rosel PE, D'Agrosa C, Read AJ (2003) Improving management of overlapping bottlenose dolphin ecotypes through spatial analysis and genetics. Mar Mamm Sci 19: 502-514

US Department of Commerce, NOAA, NGDC (National Oceanic and Atmospheric Administration, National Geophysical Data Center) (2006) 2-minute Gridded Global Relief Data (ETOPO2v2). Available at www.ngdc.noaa. gov/mgg/fliers/06mgg01.html

> Wang Z, Bovik AC, Sheikh HR, Simoncelli EP (2004) Image quality assessment: from error visibility to structural similarity. IEEE Trans Image Process 13:600-612

- Wessel P, Smith WHF (1998) New, improved version of generic mapping tools released. Eos Trans AGU 79:579

Submitted: January 13, 2011; Accepted: October 7, 2011 Proofs received from author(s): January 17, 2012 